\title{
Molecular evidence of Anaplasma phagocytophilum in wild boar (Sus scrofa) in Belgium
}

\author{
Adrien Nahayo ${ }^{1}$, Marjorie Bardiau², Rosario Volpe ${ }^{1}$, Jessica Pirson¹, Julien Paternostre ${ }^{1}$, Thomas Fett ${ }^{1}$ \\ and Annick Linden ${ }^{1 *}$
}

\begin{abstract}
Background: Anaplasma phagocytophilum is a tick-borne pathogen of veterinary and human importance. Both ticks as vectors and vertebrates as reservoir hosts are essential for the cycle maintenance of this bacterium. Currently, the whole range of animal species reservoirs for $A$. phagocytophilum in natural environment is still unknown. Therefore, the aim of this study was to estimate the prevalence of infection with A. phagocytophilum in the wild boar population in southern Belgium.
\end{abstract}

Results: In the frame of a targeted surveillance program, 513 wild boars were sampled during the hunting season 2011. A nested 165 rRNA PCR was used to screen the presence of A. phagocytophilum DNA in spleen of boars. Within 513 samples, 5 (0,97\%) were tested PCR positive and identification was confirmed by sequencing.

Conclusions: This study gives the first insight of presence of A. phagocytophilum in wild boars in southern Belgium.

Keywords: Wild boars, Ixodes, Anaplasma phagocytophilum, Belgium

\section{Background}

Anaplasma phagocytophilum is a tick-transmitted pathogen causing granulocytic anaplasmosis in human (HGA), equine and canine granulocytic anaplasmosis and tickborne fever in ruminants [1]. The epidemiology of $A$. phagocytophilum is closely related to the ecology of its main vector, namely the hard tick of the Ixodes genus. The most representative vectors include $I$. ricinus in Europe, I. persulcatus in Asia, I. scapularis in Eastern and Mid-Western United States and I. pacificus in California [2]. Although their vectorial implication has not been evidenced, A. phagocytophilum has also been detected in non-Ixodes hard ticks, such as Boophilus, Dermacentor, Hyalomma, and Rhipicephalus [3-5]. The bacterium is transstadially transmitted by the vector ticks but there is no evidence of transovarial transmission [6,7]. Therefore, both mammalian reservoirs and vector ticks are essential for the cycle maintenance of $A$. phagocytophilum.

In Europe, wild cervids in particular roe deer (Capreolus capreolus) are recognized as competent hosts for $A$. phagocytophilum $[8,9]$. The presence of this bacterium

\footnotetext{
* Correspondence: a.linden@ulg.ac.be

${ }^{1}$ Surveillance Network of Wildlife Diseases, Department of Infectious Diseases, Faculty of Veterinary Medicine, University of Liege, Liege, Belgium Full list of author information is available at the end of the article
}

has also been reported in other wild animals, such as birds and rodents $[3,6,8]$ but the whole range of animal species reservoirs for this bacterium in natural environment is still unknown. The presence of $A$. phagocytophilum in wild boars has been documented in several Eastern European countries [10-13], and also in Japan [14]. However, the role of wild boars in the epidemiology of A. phagocytophilum is not fully elucidated.

In Belgium as in other European countries, a steady increase of wild boar populations has been observed over the last twenty years. From 1987 to 2007, according to the official census of the Department of Nature and Forestry, the estimated hunting bags of wild boar in southern Belgium $\left(16,844 \mathrm{~km}^{2}\right)$ increased from 6,000 to 22,000 heads [15]. The higher abundance of wildlife and the increased contact between wildlife, domestic animals and human populations raises the risk for outbreaks of tick borne diseases, and then the difficulty of implementing surveillance and control measures [16].

The granulocytic anaplasmosis due to A. phagocytophilum is the most widespread tick borne infection in animals [17]. Although the disease is known quite a long time in veterinary medicine, the observed increasing number of clinical and/or asymptomatic cases of HGA during the two last decades mainly in United States [18] but 
also in Europe, has generated growing public health interest in this zoonosis. Recently, Cochez and co-workers reported 111 confirmed cases of HGA between 2000 and 2009 in Belgium [19]. Despite interest for this pathogen, epidemiological data are scarse and there is few informations concerning $A$. phagocytophilum infections in wild boars in Western Europe, even though they are one of the most abundant big game species.

Therefore, the aim of this study was to estimate the prevalence of infection with $A$. phagocytophilum in the wild boar population in southern Belgium using PCR targeting gene coding for the $16 \mathrm{~S}$ ribosomal RNA.

\section{Results and discussion}

Within 513 spleens tested, 5 samples were tested positive and confirmed to be infected with $A$. phagocytophilum corresponding of CE18 (Genbank accession number GQ450278.1), and Dama 35 (Genbank accession number GQ450276.1) strains by sequencing analysis. This prevalence of $0.97 \%$ (95\% IC: $0.12-1.82$ ) in wild boars is surprisingly low compared to that previously detected in roe deer (85.6\%) collected in the same region [20]. This discrepancy is also reported in other European studies. Wild cervids are important hosts for I. ricinus, the main vector of $A$. phagocytophilum. These species, especially roe deer, are largely infected by this bacterium $[9,10,21]$. In certain regions of Germany, the prevalence of $A$. phagocytophilum in roe deer reached 95\% [22] and even 100\% [23]. The role of these ungulates as competent reservoir for $A$. phagocytophilum is established [9,11].

Regarding wild boars, the situation is less clear. As in the present study, A. phagocytophilum has been reported with low prevalence in other countries such as the Czech Republic [11], Slovenia [12] and Romania [24] with rates of infection of 3 to $4 \%$. Higher prevalences were detected in wild boars sampled in Poland (12\%) and in the Czech Republic (14\%) in region close to the Austrian border $[13,10]$. In contrast, studies performed in Austria and North of Spain failed to detect any infected boars by $A$. phagocytophilum $[21,25]$. This low prevalence in wild boars supports the hypothesis that these animals can be naturally infected but capable to control infection. One of the pathways for controlling A. phagocytophilum infection may be the activation of innate immune responses and cytoskeleton rearrangement in order to promote phagocytosis and autophagy [26].

A. phagocytophilum is a single species but there is a genetic heterogeneity within the species and many closely related strains are described that differ in vectors, host preferences, geographical distribution but also pathogenicity [27]. All strains circulating in wild hosts are not infectious for humans. As an example, the main reservoir for human pathogenic strains in North America is the white-footed mouse (Peromyscus leucopus) while the white-tailed deer (Odocoileus virginianus) is reservoir for strains non infective for humans [28]. In Europe, cervids harbor mostly $A$. phagocytophilum strains that are not detected in humans $[10,21]$ but one study [22] reported that red deer may be infected with strains infectious for humans. Interestingly, human pathogenic strains of $A$. phagocytophilum have been detected in wild boars in Slovenia, Poland and the Czech Republic, suggesting that these ungulates may represent a potential reservoir for strains associated with HGA $[10,12,13]$. Further studies are needed to elucidate the role of wild boars in the epidemiology of $A$. phagocytophilum and to determine if strains detected in wild boars in Belgium are humanpathogenic strains.

\section{Conclusions}

Our data show that wild boars can be naturally infected by $A$. phagocytophilum in southern Belgium. The low prevalence infection detected in the present work is in accordance with results from previous studies and suggest that wild boars could play a less important role than cervids as reservoir for A. phagocytophilum. However, as they are particularly abundant, if they were found to harbor strains pathogenic to humans, they may represent a significant source of infection for people carrying out outdoor activities.

\section{Methods}

\section{Study area}

The study was conducted in Southern Belgium (Region of Wallonia, $\mathrm{N} 44^{\circ} 42^{\prime}$, E06 $37^{\prime}$ to $\mathrm{N} 49^{\circ} 42^{\prime}$, E06 $37^{\prime}$ ). Animals were sampled in 29 forest districts $\left(13,000 \mathrm{Km}^{2}\right)$ known to shelter wild boars (Figure 1).

\section{Target population and sampling design}

In region of Wallonia, the population of wild boars was estimated to 25,000 heads in 2011 [15]. A two-stage cluster sampling was realised. Firstly, some hunting areas were randomly chosen in each forest district and, secondly, some animals were randomly sampled in each hunting area. Forest districts are different related to their wild boars density but an ideal proportional allocation was not possible due to field constraints.

In the frame of a targeted surveillance program previously described [29], 513 boars were sampled during the hunting season (from 1st October to 31st December) in 2011. They had been shot by accredited hunters in the framework of the Wallonia Surveillance Network of Wildlife Health that had been established a decade ago by a specific ministerial decree $\left(n^{\circ} 43.01 .03 / D N E / 2010\right.$ from the Public Service of Wallonia). Hunters, scientists and the public authorities concerned all comply with the Convention on Biological Diversity and the Convention 


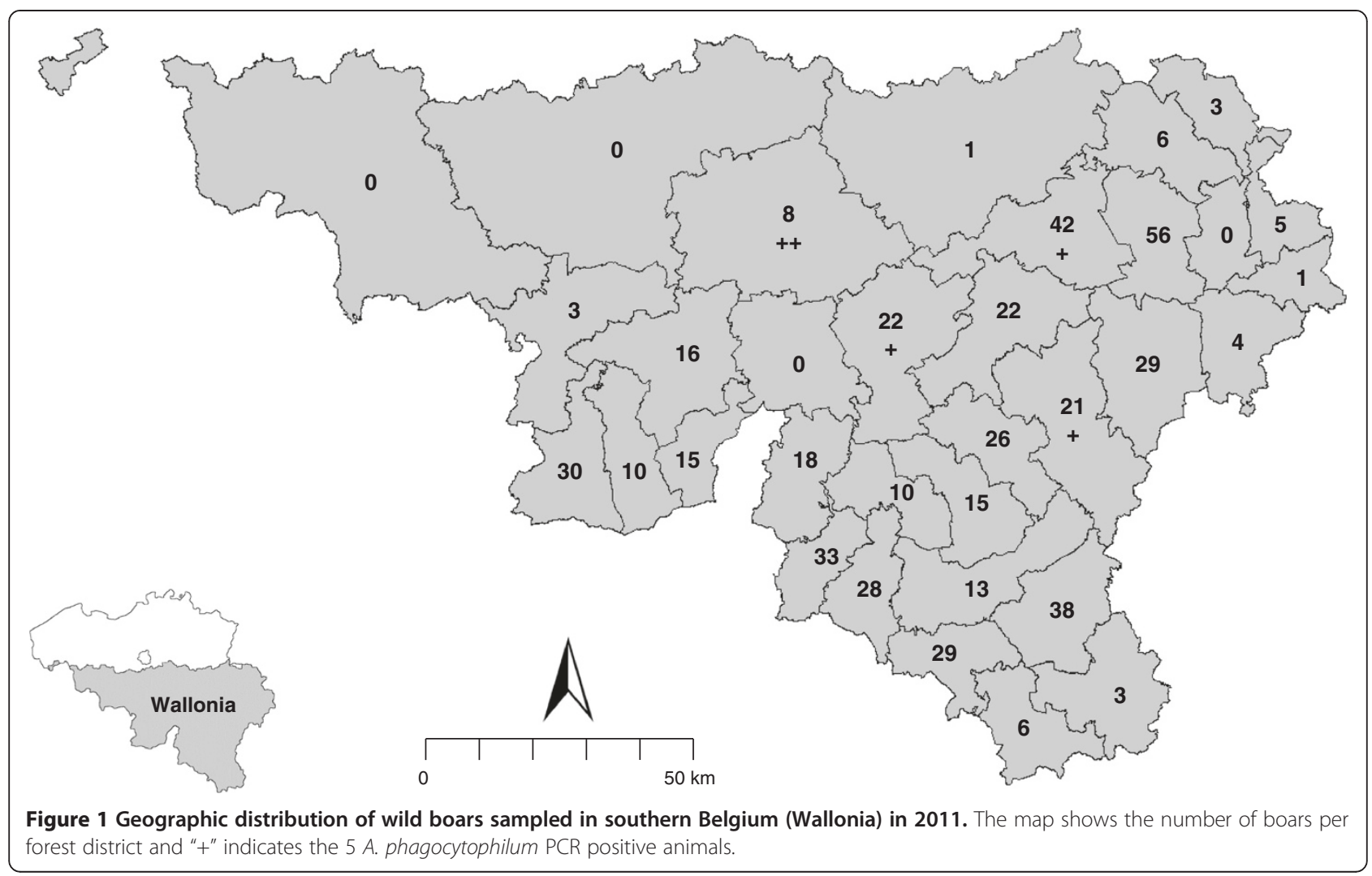

on the Trade and Endangered Species of Wild Fauna and Flora.

All animals were necropsied in the field, within 2 to 3 hours after shot. Individual postmortem examinations included determination of sex, age, body weight, and body condition. Age was determined on the basis of tooth eruption patterns and weight [30]. Animals were classified as juveniles (less than 1 year old), sub-adults (between 12 and 24 months old) and adults (over 2 years old) (Table 1). After examination of the intact whole body, the abdominal, thoracic, and naso-buccal cavities and corresponding

Table 1 Distribution of hunter-killed wild boars $(n=513)$ sampled in southern Belgium in 2011 (316 in October, 185 in November and 12 in December)

\begin{tabular}{lllll}
\hline Age group & \multicolumn{3}{c}{ Gender } & Total \\
\cline { 2 - 4 } & Females & Males & Gender $\mathbf{n c}$. \\
\hline Adults: > 2 years & $73(1)$ & 76 & 1 & $\mathbf{1 5 0}$ \\
Sub adults: $\mathbf{1 - 2}$ years & 32 & 34 & 0 & $\mathbf{6 6}$ \\
Piglets: > $\mathbf{6}$ months & $87(2)$ & $97(1)$ & 3 & $\mathbf{1 8 7}$ \\
$\quad 34(1)$ & 22 & 3 & $\mathbf{5 9}$ \\
Age group nc. & 24 & 25 & 2 & $\mathbf{5 1}$ \\
Total & $\mathbf{2 5 0}$ & $\mathbf{2 5 4}$ & $\mathbf{9}$ & $\mathbf{5 1 3}$
\end{tabular}

In parentheses: 5 Wild boars tested PCR positive for A. phagocytophilum ( 2 animals in October and 3 in November 2011).

nc.: not communicated. organs were checked. Afterwards, a piece of spleen tissue was collected and transported to the laboratory within 24 hrs for storage at $-20^{\circ} \mathrm{C}$ until DNA extraction.

\section{DNA extraction and PCR amplification}

From $50 \mathrm{mg}$ of spleen pulp tissue, total DNA was extracted using the DNAzol ${ }^{\circ}$ reagent purification method $\left(\right.$ Invitrogen $\left.^{\mathrm{rm}}\right)$ according to the manufacturer's protocol. After extraction, quality and quantity of yielded DNA were evaluated using a spectrophotometer (NanoDrop ND-1000, Thermo Scientific) and then stored at $-20^{\circ} \mathrm{C}$ until PCR reaction.

The yield DNA was tested with a 16S rRNA nested PCR. The first PCR amplifies a $1462 \mathrm{bp}$ fragment common to all Anaplasma and Ehrlichia species using the specific primers EC9 (5'-TACCTTGTTACGACTT-3') and EC12A (5'-TGATCCTGGCTCAGAACGAACG-3') while the second using the specific primers SSAP2F (5'-GCTGAATGTGGGGATAATTTAT-3') and SSAP2R (5'-ATGGCTGCTTCCTTTCGGTTA-3') amplifies a specific 641 bp fragment of the 16S rRNA Anaplasma phagocytophilum gene [31]. The PCR protocol has been adapted from the original one. The first amplification was performed as following: preliminary denaturation of $2 \mathrm{~min}$ at $95^{\circ} \mathrm{C}$; 40 cycles, each cycle consisting of: 30 s at $95^{\circ} \mathrm{C}$, 30s at $52^{\circ} \mathrm{C}$, and $90 \mathrm{~s}$ at $68^{\circ} \mathrm{C}$; final elongation of $5 \mathrm{~min}$ at $68^{\circ} \mathrm{C}$. The second amplification was performed as following: 
preliminary denaturation of $2 \mathrm{~min}$ at $95^{\circ} \mathrm{C} ; 40$ cycles, each consisting of: $1 \mathrm{~min}$ at $95^{\circ} \mathrm{C}, 1 \mathrm{~min}$ at $56^{\circ} \mathrm{C}$, and $1 \mathrm{~min}$ at $68^{\circ} \mathrm{C}$; final elongation of $5 \mathrm{~min}$ at $68^{\circ} \mathrm{C}$. One $\mu \mathrm{l}$ of DNA template in first PCR and one $\mu$ l of first amplification products in second were screened, using the above mentioned primers and $0.25 \mu \mathrm{l}$ of Taq DNA polymerase (NEB), following the manufacturer's instruction. Negative and positive controls were performed by adding either doubly distilled water or DNA from cultured Anaplasma phagocytophilum diluted at 1/100 instead of DNA samples. The amplified products were preliminarily electrophorezed on E-gel (Invitrogen), and visualized after agarose gel electrophoresis in standard conditions, stained with $2 \%$ Midori green DNA stain, (NIPPON Genetics, $\mathrm{GmbH}$ ) and then visualized under UV light.

The positive amplified products were purified and sequenced by GATC Biotech.

\section{Competing interests}

The authors declare that they have no competing interests

\section{Authors' contributions}

AN performed the field work, collected the samples, analysed the data and drafted the manuscript. MB and TF carried out and supervised the laboratory work including molecular analysis and sequencing. RV, JP and JP collaborated for the field sampling. AL was the project leader, supervised the study and contributed to the draft. All authors read and approved the final manuscript.

\section{Acknowledgements}

This study was supported by a grant from the Public Service of Wallonia. The authors are grateful to the Belgian Development Agency (BTC).

The authors thank P. Heyman and C. Cochez (Reference Laboratory for Vector-Borne Diseases, Queen Astrid Military Hospital, Brussels, Belgium ) for scientific advices and Dr Cornelia Silaghi (Ludwig Maximilians University, Munich, Germany) for generous gift of A.phagocytophilum positive control.

\section{Author details}

${ }^{1}$ Surveillance Network of Wildlife Diseases, Department of Infectious Diseases, Faculty of Veterinary Medicine, University of Liege, Liege, Belgium. ${ }^{2}$ Bacteriology, Department of Infectious Diseases, Faculty of Veterinary Medicine, University of Liege, Liege, Belgium.

\section{Received: 16 September 2013 Accepted: 14 March 2014}

Published: 2 April 2014

\section{References}

1. Woldehiwet Z: The natural history of Anaplasma phagocytophilum. Vet Parasitol 2010, 167:108-122.

2. Stanek G, Wormser PG, Gray J, Strle F: Lyme borreliosis. Lancet 2012, 379:461-473.

3. de la Fuente J, Naranjo V, Ruiz-Fons F, Hofle U, de Mera IG F, Villanua D, Almazan C, Torina A, Caracappa S, Kocan KM, Goltazar C: Potential vertebrate reservoir hosts and invertebrate vectors of Anaplasma marginale and Anaplasma phagocytophilum in central Spain. Vector-Borne Zoonotic Dis 2005, 5:390-401.

4. Naranjo V, Ruiz-Fons F, Hofle U, de Mera IG F, Villanua D, Almazan C, Torina A, Caracappa S, Kocan MK, Gortazar C, de la Fuente J: Molecular epidemiology of human and bovine anaplasmosis in Southern Europe. Ann NY Acad Sci 2006, 1078:95-99.

5. Wirtgen M, Nahayo A, Linden A, Losson B, Garigliany M, Desmecht D: Detection of Anaplasma phagocytophilum in Dermacentor reticulatus ticks. Vet Rec 2011, 168:195.

6. Ogden NH, Bown K, Horrocks BK, Woldehiwet Z, Bennett M: Granulocytic Ehrlichia infection in ixodid ticks and mammals in woodlands and uplands of the U.K. Med Vet Entomol 1998, 12:423-429.
7. Telford SR 3rd, Dawson JE, Katavolos P, Warner CK, Kolbert CP, Persing DH: Perpetuation of the agent of human granulocytic ehrlichiosis in a deer tick-rodent cycle. Proc Natl Acad Sci U S A 1996, 93:6209-6214.

8. Liz JS, Anderes L, Sumner JW, Massung RF, Gern L, Rutti B, Brossard M: PCR detection of granulocytic ehrlichiae in Ixodes ricinus ticks and wild small mammals in western Switzerland. J Clin Microbiol 2000, 38:1002-1007.

9. Alberdi MP, Walker AR, Urquhart KA: Field evidence that roe deer (Capreolus capreolus) are a natural host for Ehrlichia phagocytophila. Epidemiol infect 2000, 124:315-323.

10. Petrovec M, Sixl W, Schweiger R, Mikulasek S, Elke L, Wust G, Marthe E, Strasek K, Stunzner D, Avsic-Zupanc T: Infection of Wild animals with Anaplasma phagocytophila in Austria and Czech Republic. Ann NY Acad Sci 2003, 990:103-106

11. Hulinska D, Langrova K, Pejcoch M, Palvasek I: Detection of Anaplasma phagocytophilum in animals by real-time polymerase chain reaction. APMIS 2004, 112:239-247.

12. Strasek SK, Bidovec A, Malovrh T, Petrovec M, Duh D, Avsic-Zupanc T: Detection of Anaplasma phagocytophilum in wild boar in Slovenia. Clin Microbiol Infect 2009, 15:50-52.

13. Michalik J, Stanczak J, Cieniuch S, Racewicz M, Sikora B, Dabert M: Wild boars as hosts of human-pathogenic Anaplasma phagocytophilum variants. Emerg Infect Dis 2012, 18:998-1001.

14. Masuzawa T, Uchishima Y, Takashi F, Okamoto Y, Muto M, Koizumi N, Yamada A: Detection of Anaplasma phagocytophilum from Wild Boars and Deer in Japan. Jpn J Infect Dis 2011, 64:333-336.

15. Cellule Etat de l'environnement wallon: Tableau de bord de l'environnement wallon 2010, Edition SPW-DGARNE-DEMNA-DEE (DG: C. Delbeuck). 2010. ISBN : 978-2-8056-0017-3

16. Gortazar C, Ferroglio E, Hofle U, Frölich K, Vicente J: Diseases shared between wildlife and livestock: a European perspective. Eur J Wildlife Res 2007, 53:241-256.

17. Stuen S: Anaplasma phagocytophilum, the most widespread tick-borne infection in animal in Europe. Vet Res Commun 2007, 31:79-84.

18. Centers for Disease Control and Prevention (CDC): Anaplasmosis. Annual Cases of Anaplasmosis in the United States, Statistics and Epidemiology. http://www.cdc.gov/anaplasmosis/stats/.

19. Cochez C, Ducoffre G, Vandenvelde C, Luyasu V, Heyman P: Human anaplasmosis in Belgium: a 10-year seroepidemiological study. Tick Tick-borne Dis 2011, 2:156-159.

20. Nahayo A, Wirtgen M, Grégoire F, Volpe R, Paternostre J, Pirson J, Linden A Anaplasma phagocytophilum infection in Roe deer (Capreolus capreolus) in southern Belgium. In Proceedings of the International Wildlife Disease Association Conference: 26 July 2012; Lyon. Edited by WDA/EWDA. Lyon; 2012:294.

21. Polin H, Hufnagl P, Hauschmid R, Gruber F, Guther L: Molecular evidence of Anaplasma phagocytophilum in Ixodes ricinus ticks and wild animal in Austria. J Clin Microbiol 2004, 42:2285-2286.

22. Scharf W, Schauer S, Freyburger F, Petrovec M, Schaarschmidt-Kiener D, Liebisch G, Runge M, Ganter M, Kehl A, Dumler S, Garcia-Perez AL, Jensen J, Fingerle V, Meli ML, Ensser A, Stuen S, von Loewenich FD: Distinct host species correlate with Anaplasma phagocytophilum ankA gene clusters. J Clin Microbiol 2011, 49:790-796.

23. Silaghi C, Kauffmann M, Lygia MFP, Pfister K, Zweygarth E: Isolation, propagation and preliminary characterization of Anaplasma phagocytophilum from roe deer (Capreolus capreolus) in the tick cell line IDE8. Ticks and Tick-borne Dis 2011, 2:204-208.

24. Kiss T, Cadar D, Krupaci FA, Bordeanu AD, Spînu M: Prevalence of Anaplsma phagocytophilum infection in European wild boars (Sus scrofa) populations from Transylvania, Romania. Epidemiol Infect 2013, 24:1-5.

25. Portillo A, Perez-Martinez L, Santibanez S, Santibanez P, Palomar AM, Oteo JA: Anaplasma spp. in wild mammals and Ixodes ricinus from the North of Spain. Vector-borne and Zoonotic Dis 2011, 11:3-8.

26. Galindo RC, Ayllon N, Strasek S, Boadella M, Beltran-Beck B, Mazariegos M, Nerea G, de la Lastra JMP, Avsic-Zupanc T, Kocan KM, Gortazar C, de la Fuente J: Gene expression profile suggests that pigs (Sus scrofa) are susceptible to Anaplasma phagocytophilum but control infection. Parasites \& Vectors 2012, 5:1-14.

27. Massung RF, Mauel MJ, Owens JH, Allan N, Courtney JW, Stafford KC 3rd, Mather TN: Genetic variants of Ehrlichia phagocytophyla, Rhode Island and Connecticut. Emerg Infect Dis 2002, 8:467-472.

28. Massung RF, Courtney JW, Hiratzka SL, Pitzer VE, Smith G, Dryden RL: Anaplasma phagocytophilum in White-tailed deer. Emerg Infect Dis 2005, 11:1604-1606. 
29. Linden A, Wirtgen M, Volpe R, Nahayo A, Pirson J, Paternostre J, Grégoire F: Surveillance of wildlife diseases in Belgium. Epidémiol et Santé anim 2011 59-60:213-215.

30. Klein F: Estimating growth rate in wild boar (Sus scrofa) using capturemark-recapture data. In Proceedings of the Symposium international sur le sanglier; Toulouse. Edited by INRA; 1984:58-67.

31. Kawahara M, Rikihisa Y, Quan L, Isogai E, Kenji T, Itagaki A, Hiramitsu Y, Tomoko T: Novel genetic variants of Anaplasma phagocytophilum, Anaplasma bovis, Anaplasma centrale, and a novel Ehrlichia sp. in wild deer and ticks on two major islands in Japan. Appl Environ Microbiol 2006, 72:1102-1109.

doi:10.1186/1746-6148-10-80

Cite this article as: Nahayo et al:: Molecular evidence of Anaplasma

phagocytophilum in wild boar (Sus scrofa) in Belgium. BMC Veterinary Research 2014 10:80.

\section{Submit your next manuscript to BioMed Central and take full advantage of:}

- Convenient online submission

- Thorough peer review

- No space constraints or color figure charges

- Immediate publication on acceptance

- Inclusion in PubMed, CAS, Scopus and Google Scholar

- Research which is freely available for redistribution 